\title{
Design and Implementation of Networked CNC Machine DNC System in Colleges and Universities Based on Internet Plus
}

\author{
JIAN Zhenghao ${ }^{1, \text { a }}$, ZOU Jinhong ${ }^{2}$ \\ 1,2 School of mechanical and Vehicular Engineering, Nanchang Institute of Technology \\ ajianzhenghaojx@163.com
}

Keywords: Internet Plus, CNC Machine Networking, DNC System, Multi-Level Control Structure

\begin{abstract}
With the modern science and technology progress, to improve the level of NC skills in colleges and universities, it is necessary to keep pace with enterprise equipment as much as possible, conform to the trend of the times, do not be eliminated, and build a networked production training as soon as possible. In order to improve the level of CNC technology, processing platform, the existing CNC machine to achieve the Internet Plus based network transformation is an inevitable choice, this paper combines the existing situation of the university of CNC machine networking DNC system design and implementation based on the Internet Plus.
\end{abstract}

\section{Introduction}

With the continuous reform of teaching mode and the rapid development of information construction, the traditional laboratory operation and management model has been unable to adapt to the current development needs of colleges and universities, so the need to establish a laboratory information, open management model to improve work efficiency and management level, the depth of network intelligence and educational wisdom to create new ideas, new methods, new technologies $^{[1]}$. Relying on the network to achieve the laboratory data of digital, network management, to facilitate the laboratory management and personnel to make decisions to avoid the blindness of investment and redundant construction, the laboratory information can be timely and accurate delivery, to achieve people, And teaching and research tasks such as the overall arrangement, the rational use of resources, improve the management level, to achieve standardized laboratory management, efficient and scientific.

CNC machine are colleges and universities that to carry out teaching practice, scientific research, personnel training and social services indispensable material basis. In the existing university CNC machine tool management system, based on the use of modern Internet Plus technology, the establishment of CNC machine to share information management platform. Through the Internet based on the network of CNC machine connected DNC system issued by the school CNC machine tool use, management of the relevant policies to publish open and shared CNC machine name, model specifications, technical indicators, service areas, administrator information, opening hours, test fees and so on.

\section{Internet Plus}

The so-called "Internet Plus" refers to the Internet-based set of information technology (including mobile Internet, cloud computing, large data technology, etc.), economic activities, social life in various sectors of the proliferation and application of various sectors ${ }^{[2,3]}$. "Internet Plus" is the 
essence of the traditional industry online, data, is the work of the online, data. "Internet Plus" connotation, fundamentally separated from the traditional sense of the "information", or the Internet to redefine the information. The Internet, which has so far been the least costly infrastructure for information processing, has the characteristics of openness, equality and transparency, so that the great potential of information / data to be suppressed in industrial society can be exploded and transformed into great productivity. Social development and progress, a new source of wealth growth. In the Internet age, information is returning to the "information as the core" of this essence.

Although the concept of "Internet Plus" is not long, but based on the above understanding, it is of great practical significance to further promote the management of CNC machine in colleges and universities.

\section{CNC machine tool DNC networking technology}

DNC is the abbreviation of Direct Numerical Control or Distributive Numerical Control, that is, direct digital control or distributed digital control technology ${ }^{[4]}$. DNC is the use of computer-controlled CNC machine for direct control of the system interface. Through the DNC interface to connect the computer and CNC machine to achieve direct communication between the computer and the machine, the NC program directly to the machine CNC system, direct control of CNC machine. DNC can make full use of resources, to maximize the machine productivity, more than one machine at the same time control, is to achieve CAD / CAM and CIMS basis. According to the hierarchical theory of computer integrated manufacturing system, DNC system is an effective means to organize NC unit, which can coordinate the production operation of the whole workshop, and realize all the processing tasks including process documents, production process, machine status All information is managed. So DNC is the basis for the realization of information, integrated manufacturing, it can be used alone, but also can be expanded into FMS and CIMS. Although the DNC form is different, but the basic components are the same ${ }^{[5,6]}$. Fig.1 illustrates a basic structure of the DNC system.

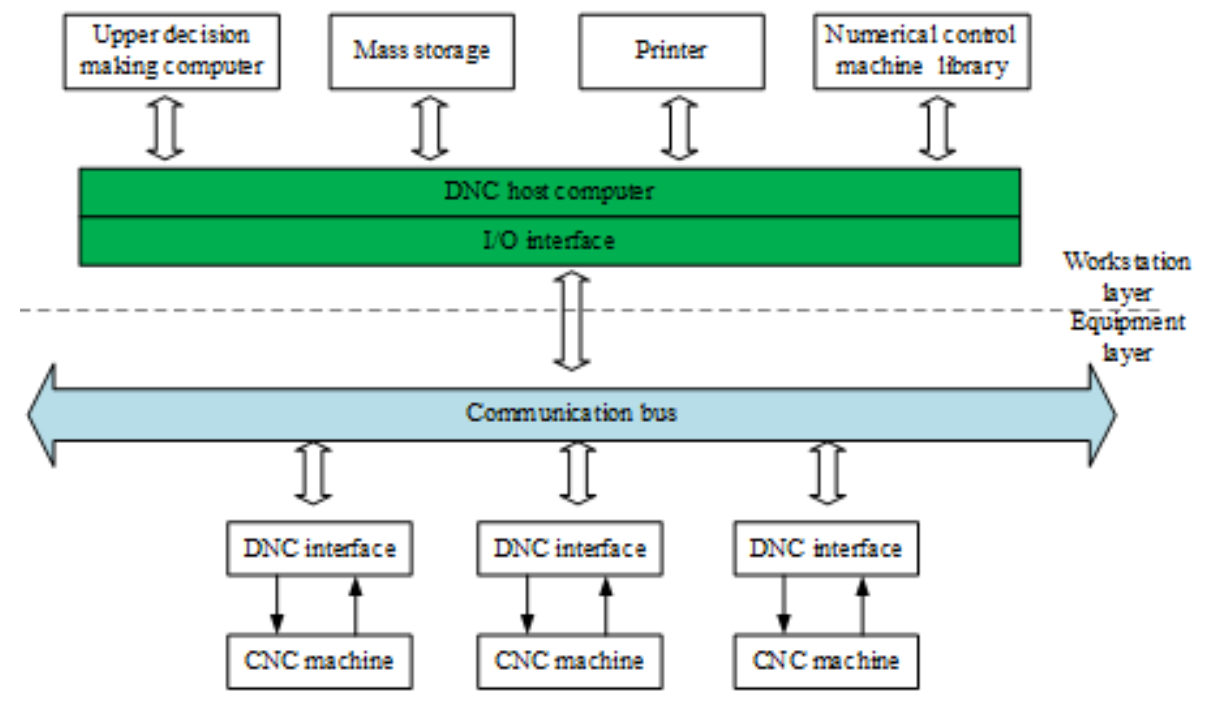

Figure 1. Basic structure of the DNC system

Usually in the choice of DNC system hardware and software to consider the factors are: 1) DNC system size; such as a small system through a DNC computer control a small number of CNC equipment, large-scale system to control the entire production workshop; 2) DNC system complexity; And the expected pre-expected goals, the realization of the function more powerful, then the system will be more complex. DNC system configuration factors such as: DNC computer 
task labor costs, shop floor, management computer system, the level of information being processed, the number of CNC, CNC number of the workshop and the workshop layer machine load and the required flexibility. Usually give priority to the specific needs of enterprises, such as the main function of the system application; degree of automation, enterprise production management model, information communication, computer structure level and other factors ${ }^{[7]}$.

\section{Design and Implement of CNC Machine Networking DNC System}

According to the CNC equipment networking statistics of the laboratory in our school, there are 42 existing machines are the recent purchase, which 19 sets of CNC lathes, 13 sets of CNC milling machine, 10 sets of processing centers, the workshop CNC system type are all with RS232 port. It is implemented as shown in Fig.2. The main technology used is multi-level control and wireless.

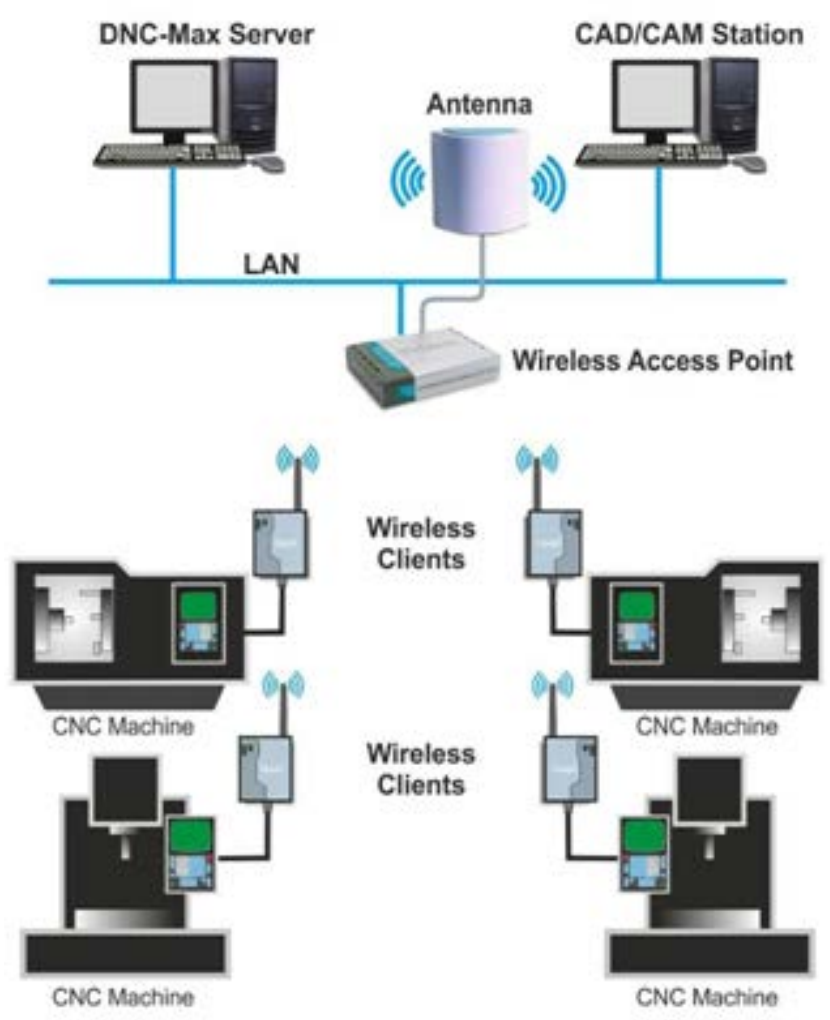

Figure 2. Implementation of CNC machine networking DNC system of the laboratory

Multi-level control structure. DNC multi-level control structure, generally tree structure. The top is used to control and coordinate the operation of the entire system, the bottom is mainly used to complete the specified special tasks. The size of the system determines the size of the DNC system layout, commonly used is two, three tree structure. In a multi-level architecture, the root node is a small computer that can be programmed automatically or graphically. And also has management system, MPP and MRP and other functions ${ }^{[8]}$. Node is a microcomputer, its role is to receive information from the upper level of the system, according to the next level of processing equipment status feedback back to the information data, the processing tasks for decomposition and scheduling, real-time processing tasks assigned to each device. The end node is usually a machine numerical control unit. It receives the processing instructions and control information from the upper level to realize the cutting feed movement and auxiliary function of the machine tool, and feeds the information to the upper level at the same time. As shown in Fig.3. 


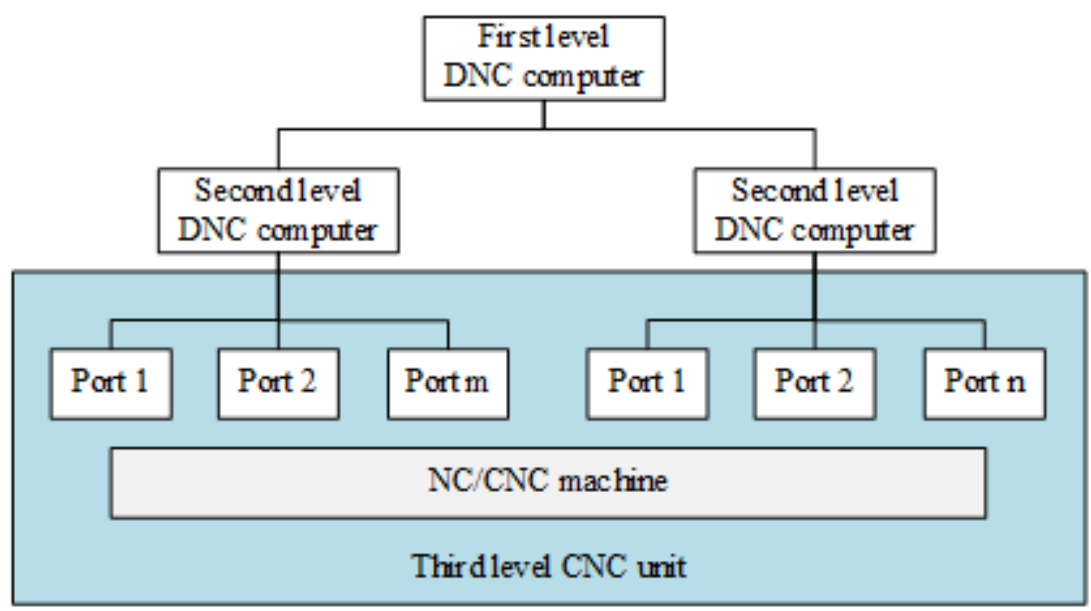

Figure 3. DNC Multi-level control structure

Wireless network DNC system. Wireless network in this program refers to the use of IEEE802.11b / g protocol wireless Ethernet network. Using a serial device The wireless network server can connect a CNC device with a serial port to an IEEE802.11b/g network to access the factory's local area network via a wireless router or switch ${ }^{[9]}$. The system structure is shown in Fig.4

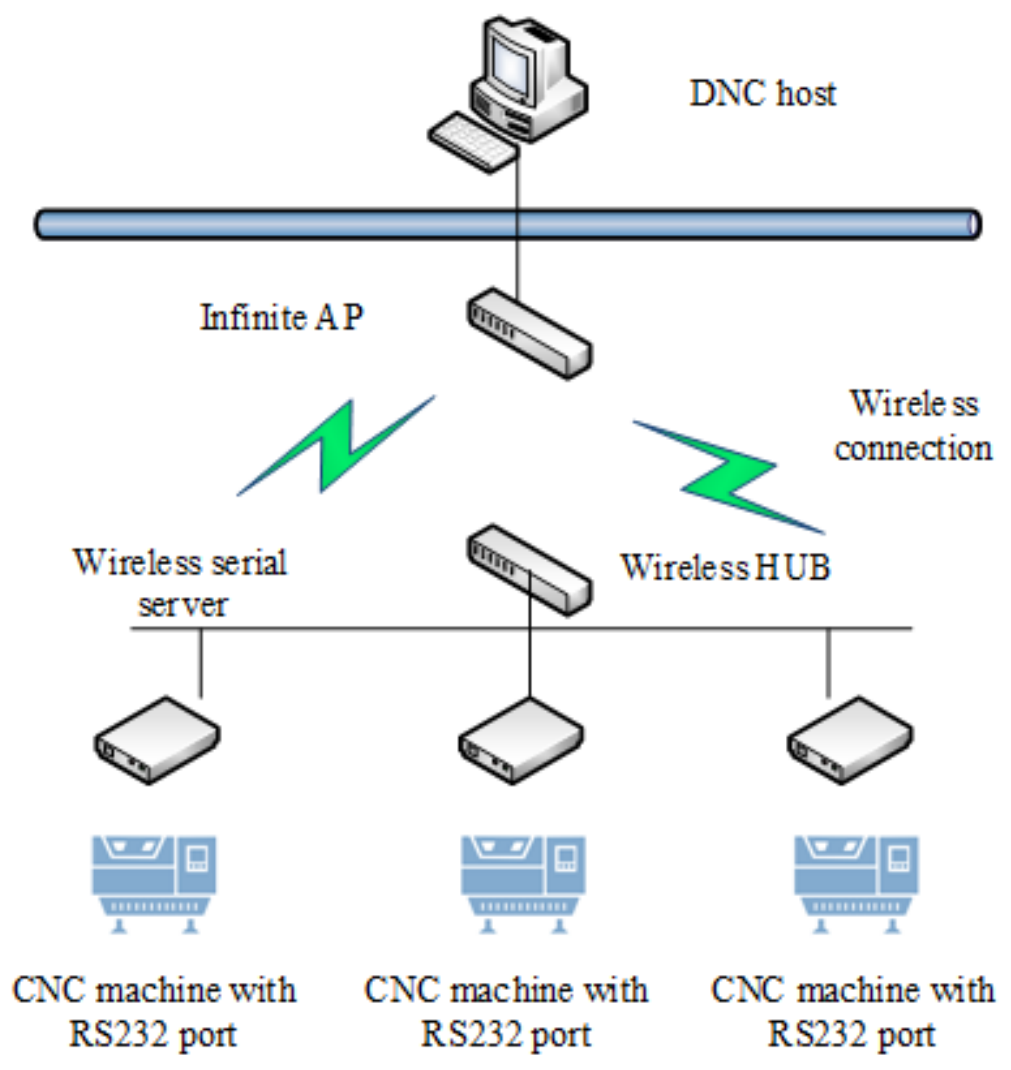

Figure 4. DNC network using wireless

The use of wireless network to build DNC system has the following characteristics: (1) All machine connections all use wireless way, eliminating the need for wiring and a long time the cable aging damage, reduce costs. (2) Easy to expand. Because all machines are wireless access, the newly acquired machine, only need to add a wireless network receiver and the corresponding settings, no additional wiring. (3) Due to the whole shop wireless. The server can be placed in any 
location. (4) Easy to fault detection. As the wireless device to reduce the fault detection link, only need to detect the key equipment can be. (5) Easy to control - due to the use of wireless networks, server computers connected to the local area network is not subject to local restrictions in any location in the workshop, can be accessed through the wireless network to the Ethernet to access the machine, understand the machine status, send Procedures and so on. Through careful analysis, considering the hardware interface and system of CNC machine tool itself, and convenient implementation of DNC integrated control, and to ensure the stability of DNC system. The training center decided to use the wired network access Ethernet program to achieve the NC machine tool network transformation.

\section{Summary}

'Internet Plus' has brought important opportunities for the construction of university laboratory information, which provides a new idea for the innovation of laboratory information management, platform construction and management mode innovation, and it is a kind of deep exploration and practice. The construction of laboratory information construction in colleges and universities should be changed and the transformation and management of innovation management mode, and comprehensively promote the construction of large-scale public platform, give full play to the support function of to CNC machine networking DNC system based on 'Internet Plus', and provide DNC system service Level, the establishment of university CNC machine networking DNC system, achieving the open and shared sharing of equipment and resource data sharing, improving laboratory management efficiency, innovation and personnel training and teaching and research services.

\section{Acknowledgements}

Science and technology project of Nanchang Institute of Technology: "Design and implementation of the CNC machine network DNC system based on Internet plus ", Number: GJKJ-15-15.

\section{References}

[1] Xiaolong Fu, Qixin Liu, Yuan Fang. Design and implementation of university level unified information system integration platform; proceedings of the Computer Sciences and Convergence Information Technology (ICCIT), 2010 5th International Conference on, F, 2010 [C]. IEEE.

[2] Xiong Wei, Xiang Fang, Zhao Zhen, Fang Jingxuan. Influence of Internet plus to International Business Development [J]. American Journal of Industrial and Business Management, 2016, 6(04): 241.

[3] Ren Jiawei, Shan Lina, Meng Xiaohui. Study on the College Politics Education Strategies and Methods in the Internet Plus Mode; proceedings of the International Conference of Young Computer Scientists, Engineers and Educators, F, 2016 [C]. Springer.

[4] Najy Raqeyah Jawad. The Role of ComputerAided Design (CAD) in the Manufacturing and Digital Control (CAM) [J]. Contemporary Engineering Sciences, 2013, 6(7): 297-312.

[5] Scheer August-Wilhelm. CIM Computer Integrated Manufacturing: Towards the Factory of the Future [M]. Springer Science \& Business Media, 2012.

[6] Ayağ Zeki, zdemir Rifat Gürcan. An intelligent approach to machine tool selection through fuzzy analytic network process [J]. Journal of intelligent manufacturing, 2011, 22(2): 163-177.

[7] Zuperl U, Cus F, Reibenschuh M. Neural control strategy of constant cutting force system in 
end milling [J]. Robotics and Computer-Integrated Manufacturing, 2011, 27(3): 485-493.

[8] Rodrigues Emanuel B, Casadevall Fernando. Control of the trade-off between resource efficiency and user fairness in wireless networks using utility-based adaptive resource allocation [J]. IEEE Communications Magazine, 2011, 49(9).

[9] Ulusoy Alphan, Gurbuz Ozgur, Onat Ahmet. Wireless model-based predictive networked control system over cooperative wireless network [J]. IEEE Transactions on Industrial Informatics, 2011, 7(1): 41-51. 